\begin{tabular}{|c|c|c|c|}
\hline $\begin{array}{l}\text { Submission: } 20 / \mathrm{Feb} / 2021 ; \\
\text { Camera ready: } 16 / \mathrm{Jul} / 2021 \text {; }\end{array}$ & $\begin{array}{l}1^{\text {st }} \text { round notif.: } 05 / \mathrm{May} / 2021 \text {; } \\
\text { Edition review: } 20 / \mathrm{Jul} / 2021 \text {; }\end{array}$ & $\begin{array}{l}\text { New version: } 30 / \mathrm{May} / 2021 \text {; } \\
\text { Available online: } 06 / \mathrm{Aug} / 2021 \text {; }\end{array}$ & $\begin{array}{l}2^{\text {nd }} \text { round notif.: } 30 / \mathrm{Jun} / 2021 \text {; } \\
\text { Published: } 06 / \mathrm{Aug} / 2021 \text {; }\end{array}$ \\
\hline
\end{tabular}

\title{
Diseño de una aplicación de lectoescritura para niños Sordos
}

\author{
Title: Design of a literacy app for Deaf children
}

\author{
José Abraham Solís Ramírez \\ Universidad Veracruzana \\ imsolis@hotmail.com
}

\author{
José Rafael Rojano-Cáceres \\ Universidad Veracruzana \\ rrojano@uv.mx
}

\begin{abstract}
Resumen
Uno de los problemas a los que se enfrenta la comunidad Sorda es que el proceso de la lectoescritura no se da de la misma manera que sus pares oyentes. La lectoescritura es una actividad que requiere del desarrollo de una conciencia fonológica para comprender que las palabras se componen por símbolos y fonemas, lo cual debido a ello es necesario la mediación bilingüe-bicultural en niños Sordos. Asimismo, los métodos de instrucción que comúnmente se utilizan se basan en el oralismo, es decir inician con la comprensión de las unidades mínimas de la palabra (sílabas y fonemas), por lo tanto, al Sordo no le genera sentido alguno debido a la carencia del sonido. Por ello, en el presente artículo se presenta el desarrollo y resultados de una aplicación que les permite a los niños sordos practicar el proceso de la lectoescritura. Lo anterior fundamentando la comunicación en el uso de la Lengua de Señas y siguiendo un método global contextualizado, el cual se contrapone a los métodos de tipo oralista en los que el sonido es importante para comenzar a comprender las palabras desde su unidad mínima. Para su validación se involucró a un grupo de usuarios Sordos que interactuaron con los contenidos desarrollados, así como se contó con la guía y aval de una asociación para la instrucción de personas Sordas y educadoras con experiencia en la enseñanza de niños Sordos. El seguimiento del progreso fue monitorizado a distancia debido a las condiciones imperantes por la Covid-19.
\end{abstract}

Palabras-Clave: Bilingüismo, Lengua de Señas, Lectoescritura, Aplicación móvil.

\begin{abstract}
One of the problems that the deaf community faces is that the literacy process does not occur in the same way as their hearing peers. Literacy is an activity that requires the development of a phonological awareness to understand that the words are composed of symbols and phonemes, which is due to this necessary bilingual-bicultural mediation for Deaf children. Likewise, the instructional methods that are commonly used are based on oralism, that is, they begin with the understanding of the minimum units of the word (syllables and phonemes), and therefore, the deaf person does not generate any meaning due to the lack of sound. Therefore, this article presents the development and results of an application that allows deaf children to practice the process of literacy. The foregoing basing communication on the use of Sign Language and following a contextualized global method, which is opposed to oralist-type methods in which sound is important to begin to understand words from their minimum unit. For its validation, a group of Deaf users who interacted with the contents developed was involved, as well as the guide and endorsement of an association for the instruction of Deaf people and educators with experience in the teaching of deaf children. The progress was monitored remotely due to Covid-19 conditions.
\end{abstract}

Keywords: Bilingualism, Sign Language, Literacy, Mobile App.

Cite as: Solís Ramírez, J. A. R., \& Rojano-Cáceres, J. R. (2021). Diseño de una aplicación de lectoescritura para niños Sordos. Revista Brasileira de Informática na Educação, 29, 1038-1059. DOI: 


\section{Introducción}

La adquisición de la lectoescritura es de carácter fundamental para la comunicación y el desarrollo en el ser humano ya que permite transmitir y conservar información de forma gráfica. Para (León, 2015) es considerada como la forma de comunicación social que permite "la transcripción gráfica del lenguaje oral". Dentro de un ámbito educativo esta tiene un papel importante, siendo esencial para el crecimiento y desarrollo del aprendiz.

El aprender a leer y escribir engloba procesos cognitivos que dependen en gran medida del contexto social en el que se encuentra el aprendiz. Para ello se han planteado dos vertientes cuya finalidad es brindar apoyo a dichos procesos, estos son: la vertiente ascendente y la vertiente descendente (Díaz, 2000, como se citó en Almanza, 2013). En la primera, también conocida como "tradicional", el estudiante es un sujeto pasivo que solo recibe información; la base fundamental de esta transferencia es el uso de grafemas, fonemas y sílabas, avanzando hasta el uso de palabras y oraciones, es decir los sonidos llevan las palabras. En la segunda vertiente, el estudiante es un sujeto activo, el cual participa del proceso de la comprensión. En esta se parte del análisis de unidades complejas como las palabras y las oraciones. Aquí se pone énfasis en un proceso analítico, que toma en consideración la experiencia del sujeto. De acuerdo con Almanza, ejemplo de estos métodos son: método de Palabras Generadoras, método Fraseológico, método de cuentos y el del lenguaje integral, entre otros.

Para una persona sorda la lectoescritura adquiere aún más importancia debido a que se convierte en su instrumento de comunicación fuera de la comunidad de personas Sordas. (Rusell \& Lapend, 2010) afirman que "la lectura y la escritura es la forma más efectiva que tiene un sordo para interactuar con la comunidad mayoritaria en la que vive". Sin embargo, el proceso de enseñanza no puede llevarse a cabo de la misma forma que con un oyente, es decir considerando una vertiente ascendente o tradicional, debido a factores como una tardía adquisición del lenguaje o la dificultad para adquirir conciencia fonológica (Figueroa \& Lissi, 2005) y sobre todo apelando al sonido como medio de dicha transferencia.

En este sentido la Organización Mundial de la Salud establece que alguien sufre de pérdida de la audición cuando no es capaz de oír tan bien como una persona cuyo sentido del oído no se encuentra afectado, es decir cuando el umbral de sonido en ambos oídos es igual o superior a $25 \mathrm{~dB}$ (OMS, 2019). Esta afección puede ser total o tener algunos grados de severidad que dependen en gran medida de cómo fue adquirida. Asimismo, la sordera también puede ser clasificada atendiendo a su etiología, el momento de su aparición, la localización de la lesión, según los oídos afectados y el grado de la pérdida auditiva (Martín E., 2010).

Por lo tanto, en el presente trabajo de investigación se propone el desarrollo de una aplicación móvil que favorezca a los niños sordos en el proceso de adquisición de la lectoescritura. Para ello se decidió optar por una vertiente descendente para su enseñanza (Almanza, 2013) la cual, como se dijo, se basa en la aplicación de un método global, así como la generación de un contexto de aprendizaje mediante el cual las palabras tienen una relación con el entorno en el que se están planteando y así, posteriormente dar paso al análisis individual de cada una, y apoyarse sobre todo en la lengua de señas para introducir una segunda lengua. Como tal, dicha aplicación se plantea para ser usada como un refuerzo para los contenidos abordados en el aula de clase y no como una herramienta de aprendizaje independiente.

Para el proceso de evaluación de la aplicación y sus contenidos se solicitó el apoyo de la asociación DIES (Difusión, Inclusión y Educación del Sordo) A.C., de la ciudad de XalapaVeracruz, México. En esta, un grupo de profesoras de Educación Especial y modelos lingüísticos Sordos trabajan con un grupo de niños con sordera profunda de entre 5 y 14 años a través del uso de la Lengua de Señas Mexicana (LSM). Mediante el acercamiento con dicha asociación y en conjunto con las profesoras se consideró primeramente aplicar algunas actividades de 
entrenamiento durante cuatro sesiones presenciales, mismas que se vieron interrumpidas por la contingencia ocasionada por el virus COVID-19. Sin embargo, gracias al rediseño de la aplicación se optó por continuar las actividades iniciales mediante un seguimiento remoto a través del uso de la aplicación.

\section{Antecedentes}

Hoy el crecimiento tecnológico está cambiando a la educación, siendo este sector el que más potencial tiene para incorporar nuevas herramientas tecnológicas para la enseñanza (FlórezAristizábal, y otros, 2019). Y debido a que estas tecnologías pueden adoptar modelos de enseñanza que estén diseñados con base en las características del alumno (Ferreira, Bueno, \& Bonacin, 2015), es importante que se integren en la educación del sordo (Marchesi, 1987). Por lo tanto, algunas propuestas tecnológicas cuyo objetivo es servir de apoyo a los sordos, principalmente niños para que puedan adquirir habilidades de lectoescritura, son las siguientes:

"The Baobab": es una aplicación desarrollada por Centro de Ciencia del Lenguaje Visual y Aprendizaje Visual de la Universidad Gallaudet. Presenta la narración de cuentos cuyo contenido está diseñado bajo una vertiente descendente e incorpora elementos de aprendizaje visual, fonológico, visual y bilingüismo. Además se apoya en el uso de elementos visuales tales como: ilustraciones, texto y videos con la interpretación en lengua de señas (Malzkuhn \& Herzig, 2013). Las desventajas que se encuentran son que esta aplicación ha sido desarrollada para la Lengua de Señas Americana (LSA) y que se distribuye para su uso con tabletas Ipad y sistema operativo IOS, en el caso del grupo de niños con los que se interactuaba, solo un padre contaba con un teléfono Iphone.

"HandsOn": es un sistema interactivo que sirve de apoyo a los sordos para practicar sus habilidades lectoescritoras y de conocimiento, completamente bilingüe, sus contenidos están orientados a sordos que se encuentran en un nivel de educación básico, hace uso de cuentos y actividades que se relacionan con temas de ciencia, geografía y literatura (Hanson \& Padden, 1992). Posee cuatro funcionalidades importantes, la primera de ellas permite leer una historia la cual se presenta en ASL e inglés escrito. Una segunda funcionalidad permite ver las historias en ASL. Otra de sus funcionalidades está orientada para que el niño traduzca la historia de ASL a inglés escrito. Finalmente, también permite al niño escribir una propia historia en inglés escrito, para que después sea traducida a ASL. Entre los aspectos que la hacen inapropiada para abordar en nuestro grupo, nuevamente se encuentra el idioma empleado ASL, asimismo que por la fecha de creación no estaba pensada para sistemas móviles como los teléfonos.

"SignBright": es una aplicación que narra una historia cuyo objetivo es promover la convivencia de los niños sordos de 2 a 5 años con sus padres. Utiliza elementos visuales que complementan la narración, tales como: ilustraciones llamativas, texto e interpretación en lengua de señas (Burton, Harbig, Melkumyan, Zhang, \& Choi, 2011). Sus principales desventajas son el uso de la ASL como medio de comunicación, así como el diseño de la aplicación para la Ipad.

"Sueñaletras": es un proyecto de la Universidad Pontificia de Chile el cual está diseñado como un apoyo a los docentes cuyo objetivo es enseñar a leer y escribir a niños sordos e hipoacúsicos de entre cuatro y diez años. Es una herramienta versátil que se adapta a la experiencia y necesidades de cada usuario, sus principales funcionalidades son el vocabulario, la lectura labiofacial, el alfabeto dactilológico y la narración de cuentos (CEDETi, 2015). Un aspecto deseable es la posibilidad de contar con distribuciones para diversas lenguas de señas, entre ellas la mexicana. Sin embargo, esta distribución está solamente disponible para su uso en computadora. En cuanto a los contenidos en LSM la aplicación no cuenta con ningún desarrollo de cuentos, para ello se probó la versión Chilena encontrándose que los cuentos solo son 
narraciones en la lengua de señas. Sin embargo, no se observa una integración global en la enseñanza para los niños.

Debido a lo anterior se puede decir que existen diversas aplicaciones que tratan de atacar el problema de la enseñanza de la lectoescritura, sin embargo este es un proceso incremental y que se acompaña de un profesor. Por ello se debe decir que las aplicaciones son un refuerzo, pero no un sustituto de la enseñanza tutorial. En el caso de los niños sordos es fundamental que este proceso también se acompañe de la lengua de señas. Las aplicaciones consideradas en la revisión principalmente están orientadas a la Lengua de Señas Americana y al uso del inglés, por este motivo no pueden ser utilizadas en el caso de México. Asimismo, ninguna de las aplicaciones consideró el desarrollo móvil, pues hoy en día en México es más probable que una familia cuente con un teléfono móvil que con una computadora. Por lo tanto se considera que el presente trabajo de investigación en una contribución al quehacer educativo como un apoyo del profesor ya que es una herramienta desarrollada con un sustento pedagógico y con la experiencia y asesoría de expertos en la educación de niños Sordos, como lo es el caso de la asociación "Difusión, Inclusión y Educación del Sordo, DIES, A.C.” que nos asesoró para su construcción.

\section{Metodología}

De forma general, para llevar a cabo el presente desarrollo propuesto se siguió la siguiente metodología. Cabe resaltar, que los puntos de dicha metodología no se narran como secciones del presente documento, pero se describen como parte de la narrativa general del mismo.

1. Realización de entrevistas con expertos en la materia, en este punto las entrevistas permiten entender las necesidades que tienen los niños sordos a través de docentes con amplia experiencia en el uso de la lengua de señas y en la enseñanza de sordos.

2. Observación in situ, la observación es una técnica socorrida en cualquier proceso de desarrollo de software, y como es bien sabido es una técnica etnográfica por antonomasia.

2.1 Acercamiento con los tutores: en esta etapa se tuvo una reunión con los tutores en la cual le fue explicado el método de trabajo, así como el objetivo de la aplicación y el por qué se consideraba importante la participación de los niños.

2.2 Aplicación de actividades de entrenamiento: se trabajaron con el grupo diferentes actividades de lectoescritura, teniendo el apoyo de un intérprete de lengua de señas mexicana.

3. Desarrollo de contenidos, el desarrollo de contenidos se ha realizado considerando los aspectos siguientes:

3.1 Selección del contenido con el experto: aquí se definen o se planean los contenidos que se habrán de reforzar en clase

3.2 Diseño de diálogos: los diálogos se diseñan considerando el contenido que se habrá de tocar. Cada diálogo se analiza para revisar que cumple con las necesidades pedagógicas del docente, así como cuenta con la claridad necesaria para su interpretación. De esta forma se realizó la creación del cuento.

3.3 Diseño en papel: como primer prototipo se crean las historietas en papel.

3.4 Validación del diálogo: en general todo material es validado por el experto para ver que cumpla con el objetivo de aprendizaje. 
3.5 Digitalización del material: en esta etapa se procede a convertir las historietas en materiales digitales en caso de que sean aprobadas.

3.6 Grabación de diálogos: cada diálogo es grabado en la lengua de señas. Para ello se puede socorrer a intérpretes, profesores usuarios de la lengua de señas y/o otros sordos.

4. Selección de las estrategias educativas, en este caso a través del diálogo con el profesor se decide la forma de enseñanza del niño. Para el caso de niños sordos se considera una estrategia descendente para la enseñanza de la lectoescritura, es decir se parte de estructuras complejas como palabras o frases para posteriormente ir bajando hasta el nivel fonológico.

5. Desarrollo de la aplicación, en este caso se decide cuál será el medio para la implementación de la solución. En el caso de este trabajo se decidió el desarrollo móvil debido a que facilita que más niños puedan usar la aplicación sin depender de computadoras en casa.

5.1 Estrategia de seguimiento, la estrategia de seguimiento permite conocer el avance del niño a través de la herramienta. Inicialmente la estrategia consistía en la revisión semanal (sabatina) con el grupo de niños. Sin embargo debido a la condición imperante por la pandemia se decidió desarrollar un módulo de seguimiento remoto, el cual registraría las interacciones, tiempos, errores y usuarios.

5.2 Validación del desarrollo, el desarrollo se fue dando de forma de prototipos. Cada uno de los mismos fue presentado al experto en materia, es decir el profesor que se encuentra frente a grupo y la validación consistió en revisar la consistencia y navegabilidad de la aplicación.

6. Evaluación de resultados, la evaluación de resultados se fundamenta en el seguimiento realizado por la estrategia de seguimiento. La evaluación consiste en el análisis de las interacciones con la aplicación de una forma cualitativa y cuantitativa.

Aunque la metodología propuesta es desarrollada ad hoc a las necesidades y consensuada con expertos en la materia, se puede decir que tiene aspectos genéricos como los propuestos en el trabajo de (Flórez-Aristizábal, y otros, 2019). Sin embargo, en la presente no se llevaron a cabo pruebas formales de usabilidad, pero gracias a la estrategia de seguimiento se tiene evidencia del uso e incluso del cumplimiento de tareas, dado que el registro de interacciones es detallado y sobre el mismo es que se basa el análisis de resultados de este trabajo.

\section{Problemática}

El niño oyente al encontrarse con una palabra por primera vez, visualiza las letras y les atribuye un significado usando el oído al pronunciar mentalmente cada una. En ese momento se construye una imagen acústica de la palabra (Clemente \& Domínguez, 2003) y a dicho proceso se le conoce como adquisición de la conciencia fonológica (Fourcade, 2007).

Así, la conciencia fonológica es una habilidad metalingüística que permite comprender que las palabras están compuestas por símbolos y fonemas. Dicho esto, las habilidades metalingüísticas son aquellas que nos permiten reflexionar y comprender aspectos importantes como los componentes o estructura de la lengua y se desarrollan a la par con la adquisición de la lengua oral en tres niveles: léxico o también conocido como conciencia de la palabra, silábico, y fonológico.

Para un niño sordo este proceso no es casual, sino que se requiere de una metodología para su instrucción debido a que no es posible formar la conciencia fonológica sin los apoyos 
adecuados. Asimismo, factores como la tardía adquisición del lenguaje y el poco conocimiento de la estructura léxica y sintáctica de la lengua, dificultan dicho proceso (Figueroa \& Lissi, 2005).

Es en este sentido que la enseñanza de la lectoescritura es un proceso complejo para el niño sordo debido a la carencia de relaciones fonológicas (sonidos) y grafemas. Asimismo como se expresó en la parte introductoria la enseñanza de la lectoescritura tradicionalmente se realiza de forma que se privilegian las relaciones de pronunciación y oralización. Por ello dicho método es totalmente carente de sentido en un niño cuya lengua natural (la lengua de señas) incluso no cuenta con una representación escrita (ágrafa).

La gran mayoría de los desarrollos tecnológicos que pretenden enseñar o reforzar la lectoescritura siguen los mismos principios que la enseñanza tradicional, por lo cual nuevamente no son apropiados para el niño sordo. Finalmente, la lengua de señas es un factor que se debe privilegiar en la transmisión de conocimiento, así como también la experiencia del sujeto.

Es en este sentido que el presente trabajo abona en los siguientes sentidos a la problemática:

- Se privilegia el uso de la lengua de señas como medio de transmisión de información.

- Se toma en consideración la experiencia del sujeto, de allí que se plasman en cuentos situaciones previamente vividas en clase de forma que se refuerce lo aprendido.

- Se considera el desarrollo basado en aplicaciones móviles para facilitar el acceso de la tecnología a los niños sordos.

- Los contenidos se han diseñado cuidadosamente siguiendo la validación de estructura y lógica con un experto. Este papel es asignado a las profesoras de niños sordos.

\section{Marco teórico}

\subsection{Sordera}

La Organización Mundial de la Salud establece que alguien sufre de pérdida de audición cuando no es capaz de oír tan bien como una persona cuyo sentido del oído no se encuentra afectado, es decir cuando el umbral de sonido en ambos oídos es igual o superior a 25dB (OMS, 2019). Dicha pérdida de la audición se puede presentar de forma leve, moderada, grave o profunda.

Autores como (Martín E., 2010) clasifican a la sordera con base en las siguientes características: a) El grado de pérdida auditiva, el cual se calcula en función del grado de intensidad en que se puede amplificar un sonido para que sea percibido por una persona sorda. La amplificación se mide en decibelios (DB); b) La frecuencia del sonido, que se mide en ciclos por segundo, y se expresa en hercios $(\mathrm{Hz})$. El oído humano percibe sonidos que se encuentran entre los $20 \mathrm{~Hz}$ y los $20,000 \mathrm{~Hz}$.

Asimismo (Martín E, 2010) menciona que la sordera puede ser clasificada de acuerdo a su etiología, momento de la aparición, localización de la lesión, según los oídos afectados y por el grado de la pérdida auditiva.

\subsection{Métodos de enseñanza de lectoescritura}

Desde hace tiempo se ha emprendido una búsqueda para poder determinar cuál es el mejor procedimiento para la enseñanza de la lectoescritura.

En este sentido, (Almanza, 2013) menciona que una de las grandes preocupaciones de los educadores es en relación con el método que se debe de utilizar para enseñar la lectoescritura y que de esta forma se pueda entender todo aquello que se lee. Asimismo, la autora identifica dos vertientes en las cuales se pueden agrupar las diferentes estrategias y métodos, las cuales son: 
vertiente tradicional, también conocida como bottom up o vertiente ascendente y la vertiente transaccional, top down o vertiente descendente.

Dentro de la vertiente tradicional el texto es el que tiene la supremacía y al lector solo se le considera como un sujeto receptor de información. Además, se hace un análisis individual de cada letra lo cual posteriormente lleva a las palabras, es decir, parten de las unidades más mínimas (grafemas y fonemas), posteriormente a la formación de sílabas y así se da paso a la formación de las palabras y frases. Los métodos basados en esta vertiente son conocidos como métodos ascendentes o métodos sintéticos y son los siguientes: método onomatopéyico, método silábico, método fónico, método alfabético, método gestual.

Por otro lado, en la vertiente transaccional el sujeto es importante ya que se considera que el participa dentro del proceso para poder comprender los mensajes textuales que recibe. Esta vertiente toma en cuenta la interacción que existe entre el lenguaje y el pensamiento al momento de leer en el cual interfiere el conocimiento previo del lector, uniéndose junto con lo que se está aprendiendo, los métodos basados en esta vertiente se conocen como métodos descendentes o analíticos y son los siguientes: método natural de Freinet, método de palabras generadoras, método léxico, método Decroly, método de lenguaje integral, método de cuentos.

\subsection{Métodos de alfabetización para sordos}

Desde que se dio paso a la educación de los sordos, se ha buscado la mejor estrategia para lograrlo. Esto trajo consigo el planteamiento de dos enfoques metodológicos, un enfoque oralista y un enfoque bilingüe (Lissi, Grau, Raglianti, Salinas, \& Torres, 2001).

El enfoque oralista plantea que el desarrollo del lenguaje, la amplificación del sonido y la lectura labiofacial, son las mejores estrategias para ayudar al sordo a integrarse en la comunidad mayoritaria en la que vive. Sin embargo, tras una serie de investigaciones que demostraron el bajo rendimiento de la educación del sordo en escuelas oralistas, se optó por una nueva estrategia, una educación basada en un modelo bilingüe (Ortiz, 2005).

\subsubsection{Bilingüismo}

El bilingüismo en la comunidad sorda hace alusión al uso de la lengua natural de la comunidad (lengua de señas) y a la lengua de la población dominante (Ortiz, 2005). Comenzó a ganar fuerza debido a las investigaciones que demostraron el potencial de la lengua de señas y su necesidad en la educación del sordo. Además, otros puntos importantes tales como:

- El estudio de lingüistas, principalmente William Stokoe, contribuyó a que la lengua de señas fuese reconocida con el estatus de verdadera lengua, estando a la altura de lenguas orales.

- La comparación en el rendimiento académico de los hijos sordos de padres señantes y los hijos sordos de padres oralistas, siendo los primeros quienes mejor nivel han demostrado.

- Las investigaciones demuestran que con la lengua de señas se puede transmitir información abstracta y compleja de manera eficaz, al igual que con lenguas orales.

- Y finalmente, la existencia de otros estudios que exponen la importancia que tiene la adquisición de dos lenguas en la competencia lingüística de los niños.

\subsubsection{La importancia del bilingüismo para los sordos}

Desde la perspectiva de (Ortiz, 2005) la primera respuesta con la cual se responde a esta pregunta es que la educación bilingüe abre las puertas para que los niños sordos cuenten con mayor facilidad para acceder a contenidos curriculares.

Por otro lado, el sordo, el principal objetivo de la educación bilingüe es que el alumno sordo pueda ser competente en dos lenguas. De esta forma el trabajar con la lengua de señas 
garantiza que el alumno pueda expresarse y desarrollarse, pero, por otro lado, es necesario que la lengua oral esté presente de forma escrita, ya que es la lengua dominante en la mayor parte del entorno, es decir, está presente en la mayor parte de las interacciones con las que contará el sordo a lo largo de su vida, de tal modo que en situaciones en las que se encuentre con personas que desconocen la lengua de señas, será necesario contar el conocimiento de la lengua dominante en su modalidad escrita para poder acceder a la información, comunicación y conocimiento (Ortiz, 2005).

\subsection{La importancia de las nuevas tecnologías en la educación del sordo}

Como se ha planteado anteriormente, una tardía adquisición del lenguaje y conciencia fonológica son factores que complican el desarrollo lectoescritor del niño sordo (Figueroa \& Lissi, 2005). Sin embargo (González, Herrera, Marín, \& Rojas, 2008) sostienen que la sordera no impide el desarrollo del niño, ya que ellos poseen las habilidades y potencial intelectivo, el cual debe de ser explotado con herramientas que se adapten a sus capacidades.

En este sentido, las nuevas tecnologías son ideales para poder captar la atención del alumno sordo, darle retroalimentación y a través de actividades visuales poner a prueba su capacidad de razonamiento (Marchesi, 1987). Es importante destacar que los recursos visuales son importantes, ya que a través de estos son capaces de comprender el contexto que les rodea, de tal modo que, al asociar información textual con representaciones visuales, es posible promover el aprendizaje y retención de contenido (González, Herrera, Marín, \& Rojas, 2008), asimismo la lengua de señas que es considerada como la lengua natural de la comunidad sorda también forma parte de estos recursos visuales, la cual al ser usada como base para introducir una segunda lengua da paso a un modelo de educación bilingüe. En este sentido, algunas de las recomendaciones para el desarrollo de herramientas tecnológicas orientadas hacia los sordos, son las siguientes:

- Tener un diseño atractivo.

- Que sea minimalista, es decir usar solo la información necesaria para resolver la tarea que se requiere.

- Usar elementos visuales para contextualizar información y tareas.

- Juegos o ejercicios con los cuales el usuario pueda explorar la lengua que está aprendiendo.

\subsubsection{La importancia de un buen diseño}

El sordo se enfrenta a serias dificultades cuando intenta interactuar con herramientas tecnológicas o interfaces que no han sido diseñadas para él. Por lo tanto, el crear herramientas que estén enfocadas en sus características y capacidades es importante ya que ayuda a mejorar las experiencias de aprendizaje (Al-Osaimi, AlFedaghi, \& Alsumait, 2009) y algunas de las consideraciones que se deben de tomar en cuenta son las siguientes:

- Texto: debe de ser sencillo y acorde a la edad del usuario para quien se está desarrollando. Además, debe de ir acompañado de un complemento visual (ilustración) y su significado en lengua de señas.

- Iconos: que estos sean claros o en su caso que tengan una seña con la cual el usuario pueda deducir la función que se llevará a cabo al ser presionado.

- Ayuda: es importante usar mensajes de ayuda, de preferencia vídeos en lengua de señas que le digan al usuario como interactuar con la herramienta.

- Diseño: los niños sordos pierden el interés en herramientas educativas de forma rápida. Por lo tanto y siguiendo la recomendación de (González, Herrera, Marín, \& Rojas, 2008) 
de sacar provecho de los recursos visuales, es importante hacer uso de elementos en la interfaz que atraigan su atención (colores, animaciones).

- Actores de lengua de señas: usar actores reales a la hora de representar significados en lengua de señas.

Por otro lado, además de la importancia de seguir estas recomendaciones también se debe de ser cuidadoso con el contenido que se incluye en estas herramientas, ya que por un lado, la tecnología logra que el aprendizaje se vuelva atractivo, pero por el otro, es decir la parte pedagógica, es necesario contar con los contenidos apropiados y asimismo diseñar los programas educativos para que las herramientas puedan ser usadas ya sea como complemento o apoyo para las actividades del docente, o para fortalecer la autonomía del estudiante y que de este modo pueda ir descubriendo el lenguaje en su forma escrita (Al-Osaimi, AlFedaghi, \& Alsumait, 2009).

Anteriormente se definió que existen dos estrategias de alfabetización, las estrategias "bottom up" y las estrategias "top down" (Almanza, 2013). De tal forma que (Malzkuhn \& Herzig, 2013) afirman que diseñar herramientas basadas en la estrategia top down es de utilidad, ya que gracias a dicha estrategia el niño se enfoca más en aprender la lengua de forma global y contextualizada lo cual posteriormente puede dar paso a interpretar las partes que la conforman. Asimismo (Malzkuhn \& Herzig, 2013) resaltan que esta estrategia se adapta a la educación bilingüe, de tal modo que, al hacer uso de la lengua de señas, imágenes, videos y demás complementos visuales en conjunto con la lengua escrita, el niño sordo es capaz de desarrollar un buen vocabulario. Por lo tanto, las herramientas tecnológicas de aprendizaje que se desarrollan bajo este enfoque le tienen que ofrecer al usuario las siguientes características:

- Visualización del lenguaje escrito.

- Interpretaciones en lengua de señas.

- Contar con ilustraciones, videos, animaciones llamativas y claras.

- Que se pueda interactuar con el contenido.

Otro factor importante que se debe tomar en cuenta a la hora de desarrollar herramientas de aprendizaje para los sordos es el contexto, ya que desde la perspectiva de (Montealegre \& Forero, 2006), el hacer uso de un contexto natural de enseñanza en la lectura y escritura ayuda a que los niños puedan ser capaces de comprender el uso del lenguaje escrito. Para ello se propone una contextualización a través de cuentos o historias, de tal forma que a través de narrativas que se complementan con ilustraciones llamativas, el niño puede experimentar y descubrir el significado de palabras escritas y signadas (Malzkuhn \& Herzig, 2013).

En este sentido (Mich, Pianta, \& Mana, 2013) proponen que a la hora de diseñar las historias para contextualizar, se tome en cuenta lo siguiente:

- Cada historia debe de proveer todo un mundo imaginario, construido a través de elementos de lenguaje e imágenes.

- Es importante que el niño se sienta atraído y las disfrute.

- Las historias deben de representar emociones o narrar actividades cotidianas.

- Tienen que ser visualmente atractivas.

Por lo tanto, tomando en cuenta lo descrito anteriormente, se propone crear una aplicación móvil para contextualizar a través de cuentos y la lengua de señas e incorporar ejercicios y retroalimentación para favorecer al proceso de la lectoescritura en niños sordos. 


\section{Desarrollo}

A lo largo del documento se ha planteado el diseño de una aplicación móvil para favorecer el proceso de la lectoescritura en niños sordos, la cual pueda ser utilizada en conjunto y como complemento a las actividades realizadas en el aula de clases. Asimismo, se han descrito los fundamentos pedagógicos para su diseño. En este sentido, después de analizar la literatura y trabajos previos, así como también con la intervención de las profesoras de la asociación DIES, se optó por el uso de cuentos y ejercicios con los cuales los niños pudiesen acercarse a la lectoescritura y practicarla. Tal y como se afirma en (Malzkuhn \& Herzig, 2013) estos son de utilidad, porque el niño se enfoca más en aprender la lengua de forma global y contextualizada lo cual posteriormente puede dar paso a interpretar las partes que la conforman.

De esta forma, el objetivo de los ejercicios es que el niño con base en la información contextual de un cuento narrado en lengua de señas, pueda reforzar su lectoescritura respondiendo ejercicios de escritura y lectura. Es decir se transmite la información en su primera lengua y luego se busca que este analice relaciones en una segunda lengua.

Los ejercicios de escritura no cuentan con número mínimo o máximo de intentos, sin embargo la aplicación los contabiliza junto con el tiempo de realización. Esto permite conocer cómo son las interacciones con los ejercicios. Asimismo, los ejercicios se van dando aleatoriamente para evitar la sola memorización.

\subsection{Requerimientos no funcionales del desarrollo}

Se definieron también algunos requerimientos no funcionales que la aplicación debería considerar para ser más accesible a los niños:

- Distribución por unidades de los cuentos y ejercicios

- Secciones de ayuda con instrucciones en LSM.

- En la sección de cuentos, el primer cuento se encuentra desbloqueado, los demás se deben desbloquear al resolver los ejercicios.

- Lectura de cuentos mediante un gesto similar al cambio de página de un libro.

- Narraciones en LSM de los cuentos.

- Controles de accesibilidad en los videos con narraciones o instrucciones.

- Distribución de ejercicios por niveles.

- Mensajes de retroalimentación que le informen al usuario si contestó de manera correcta, incorrecta.

\subsection{Creación del cuento}

Se diseñaron dos cuentos con la intención de dar un contexto al niño, el cual introduce el uso y significado de las palabras, el proceso que se llevó a cabo para diseñar los cuentos contempló las etapas definidas en la sección 3 de la metodología.

1. Selección del contenido, como primer abordaje y considerando aspectos como longitud de las sesiones y duración del curso en la asociación civil DIES, se decidió partir con el tema de saludos. La experta, Mtra. en Educación Especial Karem Contreras, comentó que esta primera temática permite al niño no solo aprender la lectoescritura, sino que también está íntimamente relacionado a su contexto diario.

2. Diseño de diálogos: los diálogos se diseñaron teniendo en cuenta las orientaciones de la Mtra. Contreras, en el sentido del tema que el niño irá desarrollando. 
3. Diseño en papel: se hizo un borrador a papel de cada una de las escenas junto con sus diálogos y narraciones, así como de algunos ejercicios relacionados con contenido de cada cuento. En la Figura 1 se aprecia el resultado de esta etapa.

4. Validación: una vez terminado el diseño, este se validó por un experto en educación especial para saber si los diálogos y narraciones eran correctos. La validación busca asegurar que los materiales (contenidos) sean correctos, de allí que a las profesoras usuarias de lengua de señas se les asignó el papel de experto.

5. Digitalización: después de haber sido validado, el cuento pasó a ser digitalizado, dicho proceso se realizó con la herramienta StoryboardThat.

6. Grabación de narraciones: posteriormente, se grabó en lengua de señas mexicana la narración del cuento.

\subsubsection{Primer cuento}

El contexto de la historia es introducir los saludos, para ello se plantea la situación de un niño llegando al salón de clases donde es saludado por sus compañeros y por su maestra. Este cuento tiene diez escenas cuya secuencia inicia en la Imagen (número) y finaliza en la Imagen (número) en donde también se muestran algunos ejercicios que se resuelven después de la lectura del cuento.

\subsubsection{Segundo cuento}

El segundo cuento sigue abordando el contexto de los saludos, pero esta vez desde una situación en la cual el personaje se encuentra con sus conocidos en distintas partes del día, así, se incluyen saludos como "buenos días", "buenas tardes", "buenas noches".
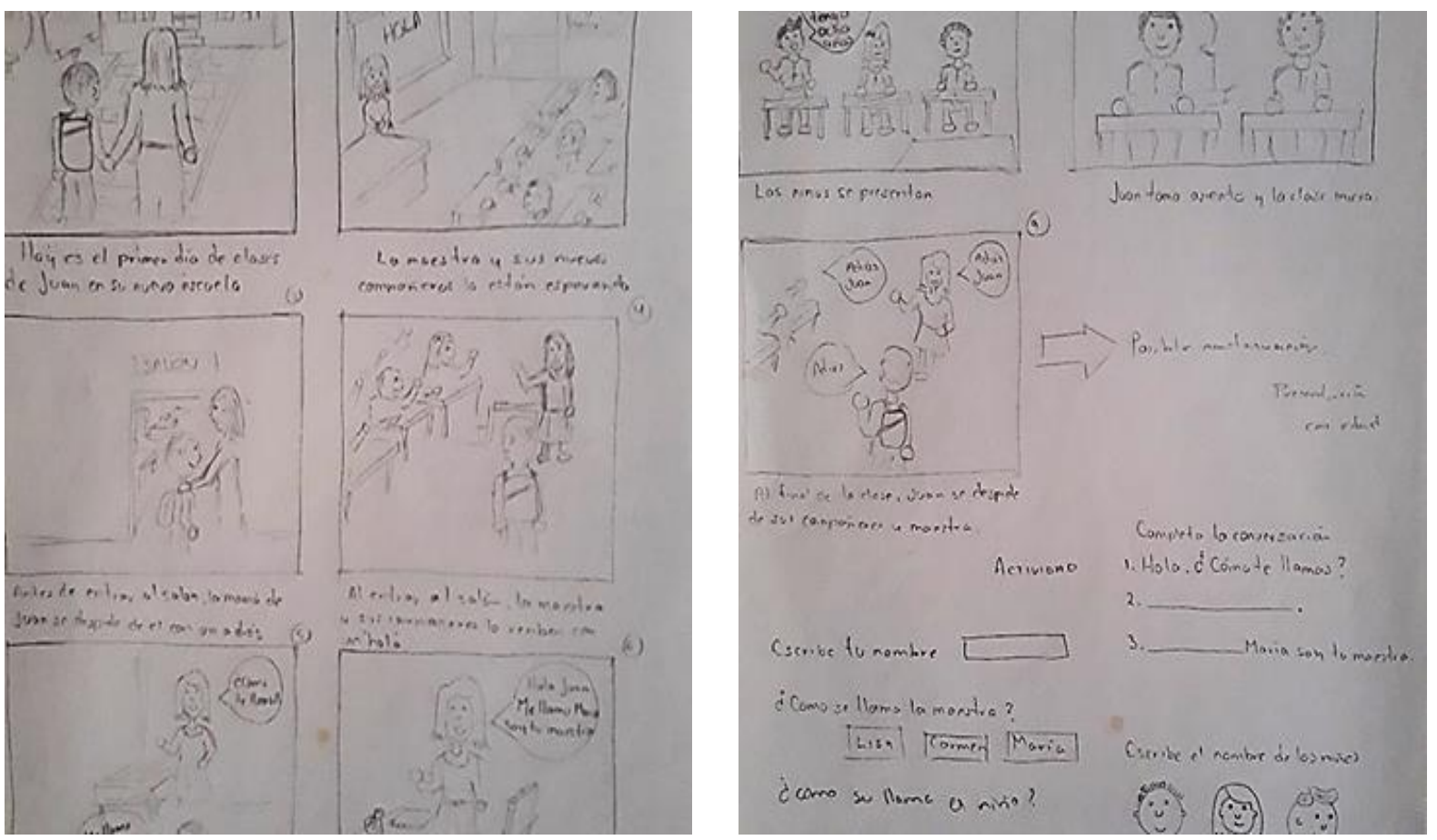

Figura 1: Escenas del primer cuento. Fuente: elaboración propia.

\subsection{Descripción de los niveles y ejercicios de la aplicación}

La aplicación se desarrolló considerando cuatro niveles de complejidad. Asimismo cada nivel cuenta con sus propios ejercicios de refuerzo. A continuación se detallan los niveles y ejercicios 
desarrollados. Nuevamente, cabe resaltar que cada nivel y ejercicio se validó con las profesoras de Educación Especial previamente a su implementación.

- Nivel uno.

a. Ejercicio uno, el usuario escribe su nombre.

b. Ejercicio dos, elegir entre cuatro opciones el nombre correcto de la maestra que aparece en el primer cuento. Se colocaron cuatro botones con las opciones de respuesta; cada botón tiene un color el cual cambia cada vez que el usuario selecciona una respuesta incorrecta.

c. Ejercicio tres, seleccionar de entre tres opciones la respuesta correcta para completar la conversación con el niño del cuento. El máximo de intentos es tres.

d. Ejercicio cuatro, elegir entre cuatro opciones el nombre correcto del niño que aparece en el cuento. Estos botones, al igual que en la segunda pregunta, cambian de color cada vez que se selecciona una respuesta incorrecta. El máximo de intentos para llegar a la respuesta correcta es cuatro.

- Nivel dos.

a. Ejercicio uno, elegir el tiempo del día que corresponde a la imagen que se muestra (buenos días, buenas tardes, buenas noches). Tres botones con las opciones de respuesta, si el usuario selecciona la incorrecta, entonces los botones cambian de posición. Este ejercicio se resuelve en tres intentos.

b. Ejercicio dos, seleccionar de entre cuatro opciones la que corresponde a un saludo. Cambiar de color los botones cada vez que se selecciona la respuesta incorrecta. El máximo de intentos para llegar a la respuesta correcta es cuatro.

c. Ejercicio tres, escribir el nombre de la maestra que aparece en el cuento.

d. Ejercicio cuatro, observar la imagen y seleccionar de entre tres opciones el saludo correcto que completa la conversación (imagen de un cielo oscuro y estrellado para ilustrar las buenas noches). Los botones también cambian de color al seleccionar la respuesta incorrecta y el máximo de intentos para llegar a la respuesta correcta es tres.

- Nivel tres

a. Ejercicio uno, ordenar los saludos y despedidas arrastrando los elementos de la interfaz sobre el lugar que les corresponde (saludos a la izquierda y despedidas a la derecha). Este se resuelve en seis intentos.

b. Ejercicio dos, escribir como me siento. Se muestran tres imágenes, cada una con un estado de ánimo, y el usuario escribe aquella con la cual se siente identificado

c. Ejercicio tres, el usuario tiene que escribir su edad (con número).

- Nivel cuatro.

a. Ejercicio uno, este se trata de escribir una carta en la cual el usuario debe de saludar, decir su nombre, cómo se siente y despedirse.

Se contempló que en aquellos ejercicios cuya respuesta correcta debía elegirse de un conjunto de opciones disponibles, los elementos de la interfaz (botones) cambiaran su posición o color al seleccionar una respuesta incorrecta y de esta manera el usuario recurra al análisis y lectura del texto en el elemento para no guiarse por sus características (color, posición, o tamaño del botón).

\subsection{Desarrollo de la aplicación}

Para el desarrollo de la aplicación se tomó como base la metodología basada en prototipos, la cual pertenece a un modelo de desarrollo evolutivo y cuyo principal objetivo es tener listo un prototipo funcional en el menor tiempo posible y hacer uso de los programas adecuados. Asimismo se consideraron los requerimientos listados en la Tabla 1. 
Tabla 1: Requerimientos de la aplicación.

\begin{tabular}{|c|l|}
\hline Categoría & \multicolumn{1}{|c|}{ Requerimiento } \\
\hline Contenidos & $\begin{array}{l}\text { Contar con cuentos y ejercicios. Agrupar los ejercicios por niveles. Aumentar la dificultad de los } \\
\text { ejercicios conforme se vaya avanzado con los contenidos. Cuentos narrados en LSM. }\end{array}$ \\
\hline Usabilidad & $\begin{array}{l}\text { Los videos deben de contar con controles de reproducción. Se podrá controlar el tamaño en } \\
\text { pantalla de cada video. Recibir retroalimentación en los ejercicios. }\end{array}$ \\
\hline Accesibilidad & Contar con secciones de ayuda en la interfaz de la aplicación \\
\hline
\end{tabular}

\subsubsection{Prototipos y primera versión de la aplicación}

De igual forma que con el diseño de los contenidos, antes de implementar la aplicación se diseñaron unos prototipos con las principales pantallas para que fueran validados por expertos en educación especial y se recibiera retroalimentación (no se realizaron evaluaciones de usabilidad y experiencia de usuario). La Figura 2 muestra el prototipo junto con el resultado al ser implementado.

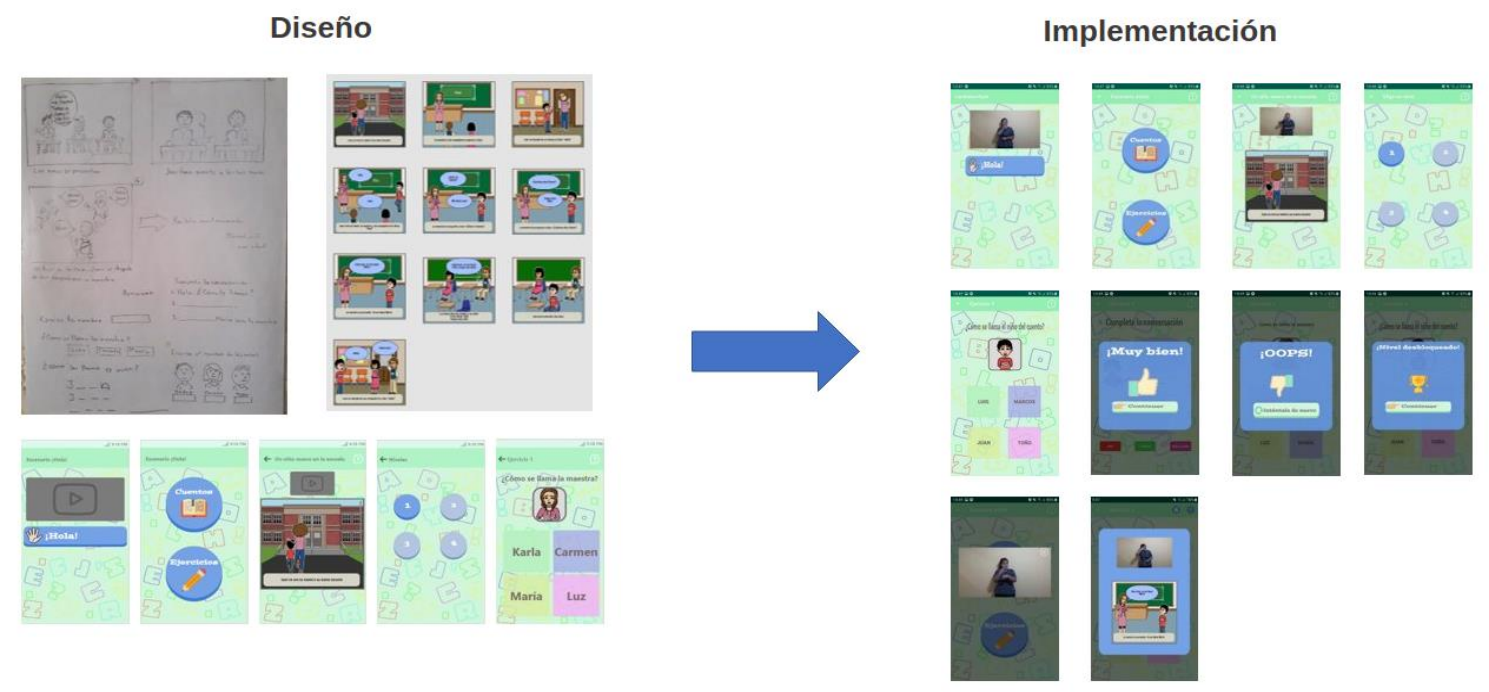

Figura 2: Diseño, prototipado e implementación.

En resumen, la primera versión de la aplicación se liberó con las siguientes características:

- Una unidad con contenidos relacionados con los saludos y despedidas.

- Tres cuentos con su respectiva ilustración e interpretación en LSM.

- Ejercicios relacionados con los saludos y despedidas, distribuidos en cuatro niveles.

- Secciones de ayuda en LSM para los ejercicios, instrucciones y demás elementos de la interfaz gráfica.

- Un ejercicio final cuya respuesta se dejó abierta para que el usuario escriba.

- Diálogos de retroalimentación, los cuales se utilizan para indicar respuestas correctas, erróneas y niveles desbloqueados.

\section{Evaluación de resultados}

Para la evaluación de resultados se partió de dos procesos, uno presencial y otro remoto. El trabajo siempre se realizó con el apoyo de las maestras de la asociación DIES (Difusión, Inclusión y Educación del Sordo), en total 3 maestras. También, se contó inicialmente de forma presencial con un grupo conformado por 15 niños de entre 5 y 12 años con hipoacusia bilateral profunda o sordera profunda, la A.C. no cuenta con mayores detalles médicos ya que no los considera necesarios para desarrollar su labor altruista. 
Inicialmente se había contemplado seleccionar niños cuyo grado escolar les permitiera tener bases sobre lectoescritura. Ya que cabe resaltar que no se espera que una sola aplicación y con tiempo de ejecución limitado desarrolle completamente dicha habilidad. Como se ha dicho el proceso de la adquisición de la lectoescritura es paulatino y requiere el apoyo adecuado de profesores usuarios de la lengua de señas. Por otro lado, a pesar de que hay trabajos relacionados en la literatura sólo consideran diversas estrategias tecnológicas pero se olvidan en gran medida del uso de la lengua natural de los sordos, así como de los diversos problemas pedagógicos para la adquisición de una lengua oral como lo es la lectoescritura. Sin embargo debido a las condiciones sanitarias solo se pudo trabajar de forma remota con 5 niños con edades de entre 9 y 12 años. Lamentablemente no se cuenta con mayores detalles de los niños dado que los padres no los proporcionaron por la falta de comunicación con los autores durante la pandemia.

Como se ha comentado, debido a la condición sanitaria imperante no fue posible cumplir con sesiones de refuerzo y evaluación presencial. La propuesta era que los niños vieran un tema en clase y lo reforzaran. Para ello en la sección 7.1.1 se comenta con detalle las actividades presenciales que se lograron hacer en un inicio para contextualizar a los niños. En la sección 7.1.2 se aborda el detalle técnico abordado para dar seguimiento a las interacciones de forma remota.

De esta forma, la sección de seguimiento o monitoreo remoto, fue una modificación a la metodología planteada donde inicialmente todo sería presencial. Dado que no se estaría en contacto con los niños la decisión para monitorear y que monitorear se basó en los siguientes puntos:

- Es posible registrar de forma remota qué actividad (véase activity ${ }^{1}$ Android) se abre en Android.

- Para cada registro se sabe fecha y hora de apertura y cierre.

- Para cada actividad se puede establecer el tiempo en el que el usuario está activo.

- Para cada actividad se puede saber el resultado del ejercicio, es decir si fue correcto o no. Así que se decidió como estrategia cuantitativa para los ejercicios de selección:

- Medir el número de intentos y fallos así como su duración asociada Y como estrategia cualitativa para los ejercicios de escritura:

- Si la resolución del ejercicio era correcta o no.

En la sección 7.1.3 se describen los criterios particulares aplicados sobre los usuarios.

\subsubsection{Aplicación de actividades de entrenamiento}

Las actividades se planearon para un periodo de dos meses, abordando durante sesiones sabatinas de 5 horas los contenidos relacionados con la aplicación.

En la Figura 3 se muestran parcialmente algunas de las actividades realizadas.

\footnotetext{
${ }^{1}$ Activity disponible en: https://developer.android.com/reference/android/app/Activity
} 

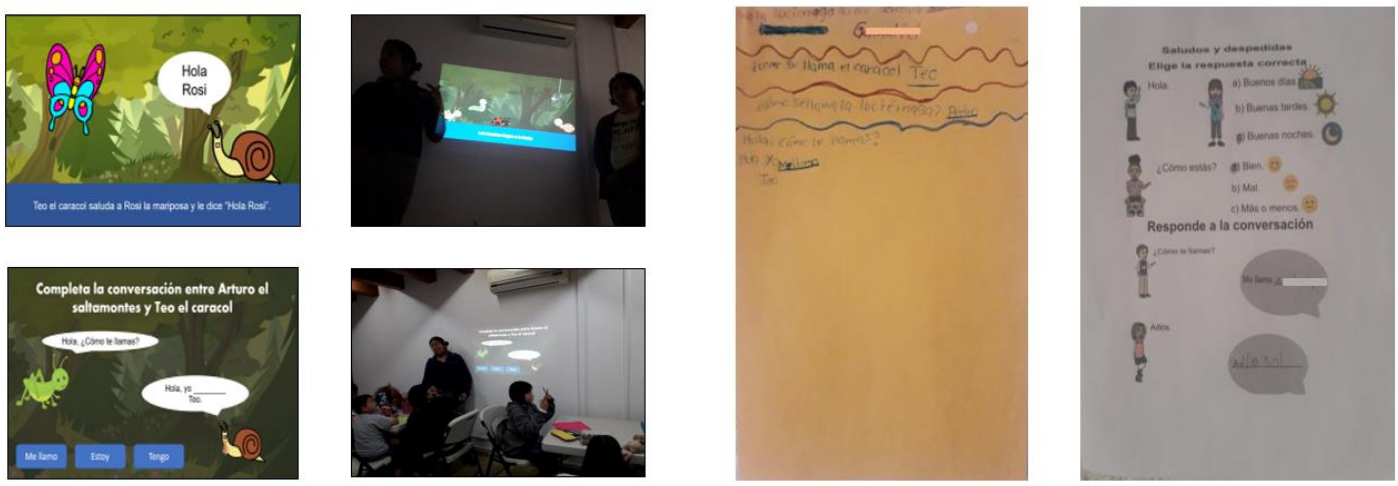

Figura 3: Resumen de las actividades aplicadas de forma presencial.

En las primeras sesiones, se pudo observar lo siguiente:

- La comunicación en el grupo se da mediante la LSM (Lengua de Señas Mexicana).

- Ante palabras desconocidas, primero se muestra una imagen descriptiva, se deletrea y finalmente se incluye en una oración para que el niño pueda apreciar el contexto de uso de esta.

- Se presta mucha atención a las expresiones faciales de los personajes en los cuentos.

- Existe un clima de competencia al momento de realizar actividades, lo cual ayuda que se tenga motivación para terminarla y ser recompensado.

Sin embargo, dada la situación ocasionada por el virus COVID-19 y siguiendo la instrucciones de las autoridades sanitarias, las sesiones tuvieron que ser canceladas y en total solo se pudieron realizar cuatro sesiones presenciales, de tal modo que se tuvo que optar por entregar la aplicación sin finalizar todas las actividades y dar seguimiento a distancia de su uso.

\subsubsection{Herramientas para el monitoreo remoto}

Como se mencionó anteriormente, debido a la situación ocasionada por el virus COVID-19 se tuvo que optar por un plan de seguimiento a distancia del uso de la aplicación en el que se utilizaron las siguientes herramientas:

1. Google Firebase: se implementó una base de datos en la que se guardaron todas las respuestas a los ejercicios que realizaron los usuarios.

2. Google Analytics: permitió conocer el tiempo promedio de uso de la aplicación, así como las posibles incidencias. instalación.

Posteriormente, se entregó la aplicación al tutor de cada niño junto con un manual para su

Gracias a Google Analytics se pudo conocer que en total 5 usuarios instalaron y usaron la aplicación, los cuales estuvieron distribuidos en las regiones de Xalapa Veracruz, Misantla Veracruz y Teziutlán Puebla, asimismo el tiempo promedio diario fue de $\mathbf{1 0}$ minutos, no se registraron fallos y las secciones más visitadas fueron las que se muestran en la Tabla 2. Tales datos sólo describen de forma general estadísticas de uso de la aplicación, pero resultan interesantes para identificar qué acciones realizan nuestros usuarios de forma concentrada. Posteriormente, con el sistema para el seguimiento individual se logró obtener con más detalle lo que el usuario realizó en cada uno de los ejercicios correspondientes a los niveles implementados en la aplicación. 
Tabla 2: Total de visitas.

\begin{tabular}{|l|c|}
\hline \multicolumn{1}{|c|}{ Ejercicio } & Total de visitas \\
\hline Ejercicio uno del nivel uno & 15 \\
\hline Ejercicio uno del nivel dos & 10 \\
\hline Ejercicio dos del nivel uno & 13 \\
\hline Ejercicio tres del nivel uno & 10 \\
\hline Ejercicio cuatro del nivel uno & 8 \\
\hline Ejercicio dos del nivel dos & 5 \\
\hline Ejercicio tres del nivel dos & 4 \\
\hline Primer cuento & 7 \\
\hline
\end{tabular}

\subsubsection{Criterios de análisis sobre los resultados obtenidos}

Para el análisis de los ejercicios cuya respuesta correcta se elegía de un conjunto de opciones, se han considerado las siguientes condiciones:

1. Número de veces que se realizó el ejercicio.

2. Total de intentos realizados para llegar a la respuesta correcta, esto aplica para aquellos ejercicios en los cuales se cuentan con varias opciones entre las cuales se encuentra la respuesta correcta. Entre menos intentos tenga un ejercicio quiere decir que se logra identificar la respuesta sin problema.

3. Tiempo que se ha tardado en responder de forma correcta cada ejercicio.

4. Si la respuesta escrita es correcta (aplica para los ejercicios en los que se tenía que escribir el nombre de un personaje del cuento o el nombre del usuario).

Por otro lado, para el análisis de los ejercicios cuya respuesta correcta se elegía de un conjunto de opciones, se han considerado las siguientes condiciones:

1. El número máximo de intentos para llegar a la respuesta correcta en unos ejercicios es de cuatro, mientras que en otros es de tres.

2. Si el número de intentos es menor al máximo de intentos requeridos para llegar a la respuesta correcta y el tiempo es alto, entonces se han analizados las opciones de respuesta.

3. Si el número de intentos es igual o mayor a los requeridos para llegar a la respuesta correcta y el tiempo es corto, entonces se ha hecho una selección al azar.

4. Si el número de intentos es menor a los requeridos y el tiempo es corto, entonces se ha comprendido el ejercicio y se identificó de forma correcta la respuesta.

\subsubsection{Ejemplo de datos recolectados y su interpretación}

En esta sección se presenta una muestra del proceso de recolección de datos desde la aplicación. La interpretación de los resultados se hizo con base a los criterios ya antes descritos:

- Diferencia entre los tiempos recolectados. Es decir si en un ejercicio un usuario finalizaba en menor tiempo un mismo ejercicio.

- Número de errores. En este caso puede ser que la conclusión fuera rápida pero con gran número de errores.

De esta forma, considere el muestreo siguiente para el ejercicio de escritura de nombre. En el mismo se presenta como contraste el resultado de la escritura del nombre entre los diferentes usuarios, las variaciones de tiempo, así como el periodo en el que este fue contestado. Cabe decir que todos los nombres no corresponden a los de los participantes. 
De esta forma, en la Tabla 3, los resultados están agrupados por cada uno de los usuarios, de tal modo que es posible realizar un análisis sobre su desempeño teniendo como factor el tiempo de respuesta y los errores:

- Para el primer usuario se pudo observar claramente que fue capaz escribir sus dos nombres y que los tiempos disminuyen cada vez que contestó el ejercicio, siendo el más alto de 34 segundos y el más bajo de 10 segundos, es decir una diferencia de 24 segundos.

- El segundo usuario registró tiempos más inconsistentes y en una ocasión su respuesta al nombre fue incorrecta, ingresando letras sin orden alguno, aun así, se pudo percibir una pequeña mejoría entre la tercera y cuarta vez que el ejercicio fue realizado.

- Con el tercer usuario durante sus periodos de interacción y respuestas si se logró percibir una mejoría significativa en los tiempos conforme fue repitiendo el ejercicio.

- Para el cuarto usuario se logró percibir una pequeña mejoría en los tiempos de finalización del ejercicio junto con sus respuestas.

- Con el quinto usuario también se logró notar una ligera mejoría en los tiempos y respuestas.

Tabla 3: Resultados al escribir el nombre.

\begin{tabular}{|c|c|c|c|c|}
\hline Usuario & Ejercicio & Respuesta & Tiempo (mm:ss) & Fecha \\
\hline \multirow[t]{3}{*}{ Primer usuario } & Escribe tu nombre & Usuario uno & $0: 34$ & $30 / 05 / 2020$ \\
\hline & Escribe tu nombre & Usuario uno & $0: 11$ & $30 / 05 / 2020$ \\
\hline & Escribe tu nombre & Usuario uno & $0: 10$ & $30 / 05 / 2020$ \\
\hline \multirow[t]{5}{*}{ Segundo usuario } & Escribe tu nombre & Usuario dos & $0: 10$ & $30 / 05 / 2020$ \\
\hline & Escribe tu nombre & hrkfn $^{2}$ & $0: 13$ & $06 / 07 / 2020$ \\
\hline & Escribe tu nombre & Usuario dos & $0: 25$ & $06 / 07 / 2020$ \\
\hline & Escribe tu nombre & Usuario dos & $0: 08$ & $06 / 07 / 2020$ \\
\hline & Escribe tu nombre & Usuario dos & $0: 18$ & $06 / 07 / 2020$ \\
\hline \multirow[t]{3}{*}{ Tercer usuario } & Escribe tu nombre & Usuario tres & $1: 23$ & $30 / 05 / 2020$ \\
\hline & Escribe tu nombre & Usuario tres & $0: 56$ & $30 / 05 / 2020$ \\
\hline & Escribe tu nombre & Usuario tres & $0: 21$ & $04 / 06 / 2020$ \\
\hline \multirow[t]{2}{*}{ Cuarto usuario } & Escribe tu nombre & Usuario cuatro & $0: 07$ & $30 / 05 / 2020$ \\
\hline & Escribe tu nombre & Usuario cuatro & 0:06 & $30 / 05 / 2020$ \\
\hline \multirow[t]{2}{*}{ Quinto usuario } & Escribe tu nombre & Usuario cinco & $0: 07$ & $27 / 05 / 2020$ \\
\hline & Escribe tu nombre & Usuario cinco & $0: 06$ & $27 / 05 / 2020$ \\
\hline
\end{tabular}

\subsubsection{Ejemplo de interacciones más representativas para tres usuarios}

En esta sección se muestran los datos de las interacciones de dos usuarios, se han seleccionado para ello los que presentaban mayor contraste a fin de visualizar cómo cada niño lleva a cabo su avance.

El usuario 1, con interacciones en la Tabla 4, fue capaz de realizar los ejercicios en los cuales se seleccionaba de entre diferentes opciones la respuesta correcta, demostrando que el número de intentos y el tiempo para llegar a dicha respuesta disminuyeron conforme repetía cada ejercicio. Por lo cual se puede decir que fue capaz de analizar cada opción disponible sin la necesidad de recurrir a una selección al azar. Asimismo, también fue capaz de demostrar que pudo escribir su nombre de forma correcta, logrando disminuir el tiempo en cada repetición del ejercicio. Únicamente no pudo comprender el ejercicio de ordenar los saludos y también el ejercicio donde tenía que escribir el nombre de la maestra (la primera vez que lo realizó). En cuanto a los demás ejercicios de escritura, los completó de forma correcta y demostró, a la hora de escribir una carta, que puede saludar, decir cómo se siente y despedirse. Por lo tanto, sí se percibió una mejoría en tiempo e intentos conforme iba interactuando con la aplicación.

\footnotetext{
${ }^{2}$ El nombre se transcribió tal y cual el usuario lo colocó, dejando ver que no fue la respuesta adecuada.
} 
Tabla 4: Resultados de las interacciones por nivel y ejercicio para el primer usuario.

\begin{tabular}{|c|c|c|c|c|c|c|}
\hline \multicolumn{7}{|c|}{ Primer usuario } \\
\hline \multicolumn{7}{|c|}{ Ingresó por primera vez el: 27 mayo de 2020} \\
\hline \multicolumn{7}{|c|}{ Fecha de corte: 3 junio de 2020} \\
\hline Nivel & Ejercicio & Intentos & Tiempo (mm:ss) & Respuesta & Fecha & Hora \\
\hline Nivel 1 & dos & 4 & $0: 25$ & Pregunta de selección ${ }^{3}$ & $30 / 05 / 2020$ & $11: 48: 41$ \\
\hline \multicolumn{7}{|c|}{ Inició de nuevo el nivel } \\
\hline \multirow{2}{*}{ Nivel 2} & dos & 1 & $0: 02$ & Pregunta de selección & $30 / 05 / 2020$ & $11: 49: 31$ \\
\hline & tres & 1 & $0: 02$ & Pregunta de selección & $30 / 05 / 2020$ & $11: 49: 33$ \\
\hline \multicolumn{7}{|c|}{ Inició de nuevo el nivel } \\
\hline \multirow{3}{*}{ Nivel 1} & dos & 1 & 0:01 & Pregunta de selección & $30 / 05 / 2020$ & $11: 49: 59$ \\
\hline & tres & 1 & $0: 01$ & Pregunta de selección & $30 / 05 / 2020$ & $11: 50: 00$ \\
\hline & cuatro & 1 & $0: 01$ & Pregunta de selección & $30 / 05 / 2020$ & $11: 50: 03$ \\
\hline \multicolumn{7}{|c|}{ Inició con el nivel dos } \\
\hline \multirow{3}{*}{ Nivel 2} & uno & 3 & 0:07 & Pregunta de selección & $30 / 05 / 2020$ & $11: 50: 57$ \\
\hline & dos & 1 & $0: 04$ & Pregunta de selección & $30 / 05 / 2020$ & $11: 51: 04$ \\
\hline & tres & 1 & 1:08 & Usuario uno & $30 / 05 / 2020$ & $11: 51: 08$ \\
\hline \multicolumn{7}{|c|}{ Inició de nuevo el nivel } \\
\hline \multirow{4}{*}{ Nivel 2} & uno & 3 & $0: 06$ & Pregunta de selección & $30 / 05 / 2020$ & $11: 52: 42$ \\
\hline & dos & 1 & $0: 01$ & Pregunta de selección & $30 / 05 / 2020$ & $11: 52: 48$ \\
\hline & tres & 1 & $0: 26$ & María & $30 / 05 / 2020$ & $11: 52: 49$ \\
\hline & cuatro & 1 & $0: 06$ & Pregunta de selección & $30 / 05 / 2020$ & $11: 53: 15$ \\
\hline \multicolumn{7}{|c|}{ Inició el nivel tres } \\
\hline \multirow{3}{*}{ Nivel 3} & uno & 1 & $0: 06$ & Pregunta de selección & $30 / 05 / 2020$ & $11: 53: 24$ \\
\hline & dos & 1 & $0: 12$ & Bien & $30 / 05 / 2020$ & $11: 53: 30$ \\
\hline & tres & 1 & $0: 25$ & 18 & $30 / 05 / 2020$ & $11: 53: 42$ \\
\hline \multicolumn{7}{|c|}{ Inició el nivel cuatro } \\
\hline Nivel 4 & uno & 1 & $3: 17$ & $\begin{array}{c}\text { Hola como estas? Cecilia } \\
\text { Yo Usuario uno bien } \\
\text { Adiós }\end{array}$ & $30 / 05 / 2020$ & $11: 57: 53$ \\
\hline
\end{tabular}

El usuario 2, con interacciones en la Tabla 5, presentó una variación entre los tiempos de uso desde en el primer periodo. En cuanto a la escritura del nombre, estos tiempos fueron inconsistentes, lo cual puede ser a causa de que el usuario no se haya involucrado completamente en su solución. Sin embargo, fue posible percibir una mejoría de tiempo en el tercer y cuarto periodo de interacción. En los ejercicios de selección de la respuesta, en algunas ocasiones se logró detectar un patrón en el cual se contestaba al azar sin hacer un análisis, pero probablemente al darse cuenta de que la respuesta no estaba determinada por las características del elemento (color, posición, tamaño), se intuye que el usuario comenzó a leer el texto o mejoró su capacidad de análisis, de tal forma que, en los siguientes periodos se pudo notar una mejoría tanto en intentos como en tiempo para responder de forma correcta.

Tabla 5: Resultados de las interacciones por nivel y ejercicio para el segundo usuario.

\begin{tabular}{|c|c|c|c|c|c|c|}
\hline \multicolumn{7}{|c|}{ Ingresó por primera vez el: 30 de mayo de 2020 } \\
\hline \multicolumn{7}{|c|}{ Fecha de corte: 3 de junio de 2020 } \\
\hline \multirow{2}{*}{ Nivel } & Ejercicio & Intentos & Tiempo(mm:ss) & Respuesta & \multicolumn{1}{c|}{ Fecha } & Hora \\
\hline \multirow{3}{*}{ uno } & dos & 3 & $0: 40$ & Pregunta de selección & $30 / 05 / 2020$ & $15: 52: 58$ \\
\cline { 2 - 7 } & tres & 1 & $0: 20$ & Pregunta de selección & $30 / 05 / 2020$ & $15: 53: 38$ \\
\cline { 2 - 8 } & cuatro & 1 & $0: 07$ & Pregunta de selección & $30 / 05 / 2020$ & $15: 54: 04$ \\
\hline \multicolumn{7}{|c|}{ Fecha de corte: 10 Julio 2020 } \\
\hline \multirow{2}{*}{ uno } & dos & 4 & $0: 29$ & Pregunta de selección & $06 / 07 / 2020$ & $10: 20: 12$ \\
\cline { 2 - 7 } & tres & 2 & $0: 19$ & Pregunta de selección & $06 / 07 / 2020$ & $10: 20: 41$ \\
\hline \multicolumn{7}{|l|}{} \\
\hline
\end{tabular}

3 “Pregunta de selección” se refiere de aquí en adelante a que el estudiante realizó una selección correcta del ejercicio. 


\begin{tabular}{|c|c|c|c|c|c|c|}
\hline \multirow{2}{*}{ uno } & dos & 1 & $0: 03$ & Pregunta de selección & $06 / 07 / 2020$ & $10: 21: 25$ \\
\hline & tres & 1 & $0: 04$ & Pregunta de selección & $06 / 07 / 2020$ & $10: 21: 28$ \\
\hline \multicolumn{7}{|c|}{ Inició de nuevo el nivel } \\
\hline \multirow{3}{*}{ uno } & dos & 1 & $0: 03$ & Pregunta de selección & $06 / 07 / 2020$ & $10: 24: 40$ \\
\hline & tres & 1 & $0: 04$ & Pregunta de selección & $06 / 07 / 2020$ & $10: 24: 43$ \\
\hline & cuatro & 4 & $0: 08$ & Pregunta de selección & $06 / 07 / 2020$ & $10: 24: 51$ \\
\hline \multicolumn{7}{|c|}{ Inició con el nivel dos } \\
\hline \multirow{3}{*}{ dos } & uno & 5 & $0: 25$ & Pregunta de selección & $06 / 07 / 2020$ & $10: 25: 15$ \\
\hline & dos & 1 & $0: 06$ & Pregunta de selección & $06 / 07 / 2020$ & $10: 25: 40$ \\
\hline & tres & 1 & $0: 18$ & Elizabeth & $06 / 07 / 2020$ & $10: 25: 46$ \\
\hline \multicolumn{7}{|c|}{ Inició de nuevo el nivel } \\
\hline \multirow{2}{*}{ dos } & uno & 3 & $0: 12$ & Pregunta de selección & $06 / 07 / 2020$ & $10: 26: 23$ \\
\hline & dos & 1 & $0: 04$ & Pregunta de selección & $06 / 07 / 2020$ & $10: 26: 35$ \\
\hline
\end{tabular}

El usuario 3, con interacciones en Tabla 6, mostró una mejoría en el tiempo a la hora de escribir su nombre, aunque una de estas respuestas tuvo que ser anulada ya que la cantidad de elementos y tiempo no coincidía con las otras respuestas, considerando como primer motivo el que quizás no se involucró por completo en la solución. Por otro lado, en los ejercicios de selección de la respuesta se pudo notar el mismo patrón que en el usuario anterior al contestar al azar en algunas ocasiones, pero probablemente al darse cuenta de que la respuesta no se encontraban en las características del elemento (color, tamaño, posición), se presume que el usuario comenzó a analizar el texto, de tal modo que en los siguientes periodos pudo notarse una mejoría en intentos y tiempo.

Tabla 6: Resultados de las interacciones por nivel y ejercicio para el tercer usuario.

\begin{tabular}{|c|c|c|c|c|c|c|}
\hline \multicolumn{7}{|c|}{ Tercer usuario } \\
\hline \multicolumn{7}{|c|}{ Ingresó por primera vez: 27 de mayo de 2020} \\
\hline \multicolumn{7}{|c|}{ Fecha de corte: 3 de junio de 2020} \\
\hline Nivel & Ejercicio & Intentos & Tiempo(mm:ss) & Respuesta & Fecha & Hora \\
\hline \multirow{2}{*}{ Nivel uno } & dos & 3 & $0: 29$ & Pregunta de selección & $27 / 05 / 2020$ & $15: 58: 02$ \\
\hline & tres & 1 & $0: 44$ & Pregunta de selección & $27 / 05 / 2020$ & $15: 58: 31$ \\
\hline \multicolumn{7}{|c|}{ Inició de nuevo el nivel } \\
\hline Nivel uno & dos & 4 & $0: 26$ & Pregunta de selección & $30 / 05 / 2020$ & 12:09:02 \\
\hline \multicolumn{7}{|c|}{ Fecha de corte: 12 de junio 2020} \\
\hline \multirow{3}{*}{ Nivel uno } & dos & 2 & $0: 24$ & Pregunta de selección & $04 / 06 / 2020$ & $17: 54: 01$ \\
\hline & tres & 1 & $0: 23$ & Pregunta de selección & $04 / 06 / 2020$ & $17: 54: 25$ \\
\hline & cuatro & 2 & $0: 15$ & Pregunta de selección & $04 / 06 / 2020$ & $17: 54: 48$ \\
\hline \multicolumn{7}{|c|}{ Inició de nuevo el nivel } \\
\hline \multirow{2}{*}{ Nivel uno } & dos & 4 & $0: 32$ & Pregunta de selección & $04 / 06 / 2020$ & $18: 13: 15$ \\
\hline & tres & 1 & $0: 18$ & Pregunta de selección & $04 / 06 / 2020$ & $18: 13: 47$ \\
\hline \multicolumn{7}{|c|}{ Inició con el segundo nivel } \\
\hline \multirow{3}{*}{ Nivel dos } & uno & 14 & $1: 28$ & Pregunta de selección & $04 / 06 / 2020$ & $18: 14: 30$ \\
\hline & dos & 1 & $0: 03$ & Pregunta de selección & $04 / 06 / 2020$ & $18: 16: 28$ \\
\hline & tres & 1 & $0: 20$ & Karla & $04 / 06 / 2020$ & $18: 16: 31$ \\
\hline
\end{tabular}

\section{Conclusiones}

Con este trabajo se logró desarrollar una aplicación móvil que permite practicar el desarrollo de las habilidades relacionadas con la lectoescritura en niños sordos. Para dicho desarrollo se siguió un método global contextualizado el cual hace uso de cuentos y ejercicios, además de que se incorporaron otros elementos importantes, tales como un diseño apropiado y acorde a las características del usuario, incluyendo la narración de cuentos en LSM, así como instrucciones y retroalimentación. Siendo todo el proceso de creación avalado por las profesoras de una 
asociación para la enseñanza de las personas sordas: "Difusión, Inclusión y Educación del Sordo (DIES), A.C.”.

Asimismo, gracias al trabajo presencial con los usuarios en la asociación DIES, se pudo conocer el ambiente de interacción y de aprendizaje. Las actividades realizadas con el grupo ayudaron a observar cómo es que cada alumno se comporta frente a ejercicios de lectoescritura. De tal modo que, al interactuar con ellos se obtuvo una importante retroalimentación que aportó más ideas para implementar otros contenidos y características que ayudaron a refinar el diseño de la aplicación.

En resumen, después de probar la aplicación con usuarios sordos se pudo comprobar que los cuentos, acompañados con ilustraciones llamativas y narraciones en lengua de señas, son una herramienta importante para practicar la lectoescritura y principalmente atender a contextualizar una situación; siendo en la aplicación el primero de los tres cuentos implementados el que más lecturas tuvo.

Con relación a los ejercicios implementados en la aplicación, en aquellos en los que se debía seleccionar la respuesta correcta de entre varias opciones se logró demostrar que en efecto hubo una reducción de tiempo conforme estos eran resueltos, asimismo, el número de intentos también mejoró. Aunque, en algunas ocasiones se pudo detectar un patrón de selección al azar, ya que los tiempos e intentos no corresponden para determinar que se hizo un análisis de cada opción. Esto es muy importante, ya que este tipo de ejercicios fueron diseñados de tal forma que las características del elemento cambiarán cada vez que el usuario interactuaba con el (color, posición), por lo tanto, se puede concluir que el diseñarlos de esta forma dio un buen resultado, ya que el usuario al percatarse de que la respuesta no la determinaban las características de dicho elemento, comenzó a analizar el texto que se encontraba en este.

Por otro lado, a la hora de escribir su nombre, los usuarios que usaron la aplicación pudieron hacerlo de forma correcta. Del mismo modo, un usuario fue capaz de escribir un texto final en el cual demostró que puede saludar, decir cómo se siente y despedirse. Será posible especular que el resultado se debió a los propios antecedentes formativos de cada niño, sin embargo eso no demerita el uso y alcance de la aplicación como un mecanismo de refuerzo de la lectoescritura, que en primera instancia era la situación buscada en las sesiones presenciales.

En los ejercicios de escritura restantes en la aplicación también se lograron obtener respuestas por parte de los usuarios, aunque tuvieron que descartarse algunas debido a que eran incorrectas. Esto es importante al dar un indicio de que posiblemente no se consultó la retroalimentación encontrada en cada ejercicio, la cual daba pistas o inclusive la respuesta a dicha actividad, de tal modo que, es necesario buscar otra manera de presentar y hacer accesibles dichas pistas o incorporar otros elementos para que las puedan identificar.

Por otro lado, este trabajo también contemplaba una serie de objetivos que se cubrieron de la forma que describe la Tabla 7.

Finalmente, como trabajo futuro, la primera línea de continuación es expandir los contenidos de la aplicación, ya que en esta primera etapa sólo se desarrolló una unidad de aprendizaje relacionada con los saludos y despedidas, por lo tanto, es posible incorporar más unidades con sus respectivos contenidos, los cuales permitan obtener mayor número de resultados con los que sea posible demostrar que hay un proceso de aprendizaje por parte del usuario. También queda pendiente el poder realizar algunas pruebas de usabilidad con los niños y contrastar las hipótesis de funcionalidad en relación a la metodología de evaluación remota. 
Tabla 7: Objetivos cumplidos.

\begin{tabular}{|c|c|}
\hline Objetivo & ¿Cómo se cumplió? \\
\hline $\begin{array}{l}\text { Desarrollar una aplicación móvil que favorezca al } \\
\text { proceso de la lectoescritura en niños sordos con } \\
\text { conocimiento previo de la LSM utilizando un método } \\
\text { global contextualizado. }\end{array}$ & $\begin{array}{l}\text { - Se planteó un proceso metodológico para su } \\
\text { implementación, en este proceso participaron los } \\
\text { expertos (profesores) y los niños a través de } \\
\text { actividades presenciales que permitieron conocer } \\
\text { y valorar su situación. } \\
\text { - Posteriormente se desarrolló la aplicación, siendo } \\
\text { validada en todo momento por las profesoras. }\end{array}$ \\
\hline $\begin{array}{l}\text { Valorar el nivel de lectoescritura de cada niño mediante } \\
\text { sesiones presenciales. }\end{array}$ & $\begin{array}{l}\text { - Se acudió a la asociación DIES y se aplicaron } \\
\text { actividades a un grupo de niños. }\end{array}$ \\
\hline $\begin{array}{l}\text { Hacer pruebas con la aplicación desarrollada en un } \\
\text { entorno con usuarios reales. }\end{array}$ & $\begin{array}{l}\text { - Se entregó la aplicación a los tutores de cada niño, } \\
\text { junto con un manual para su correcta instalación. }\end{array}$ \\
\hline Dar seguimiento a los tiempos de uso de la aplicación. & $\begin{array}{l}\text { Se implementó un sistema con la ayuda de } \\
\text { Firebase, Nodejs y VueJS para poder conocer los } \\
\text { resultados obtenidos por los usuarios en cada } \\
\text { ejercicio. }\end{array}$ \\
\hline
\end{tabular}

\section{Referencias}

Almanza, M.T. (2013). Métodos de lectura en español. The University of Texas-Pan American. [GS Search]

Al-Osaimi, A., AlFedaghi, H., \& Alsumait, A. (2009). User interface requirements for e-learning program designed for deaf children. Proceedings of the first Kuwait conference on $e$ Services and e-Systems, (págs. 1-5). doi: 10.1145/1836029.1836036 [GS Search]

Alsumait, A., Faisal, M., \& Banian, S. (2015). Improving literacy for deaf Arab children using interactive storytelling. Proceedings of the 17th International Conference on Information Integration and Web-based Applications \& Services, (págs. 1-5). doi: 10.1145/2837185.2837187 [GS Search]

Burton, M. M., Harbig, C., Melkumyan, M., Zhang, L., \& Choi, J. (2011). An evaluation of signbright: A storytelling application for sign language acquisition and interpersonal bonding amongst deaf and hard of hearing youth and caregivers. International Conference on Human-Computer Interaction, (págs. 474-478). doi: 10.1007/978-3-642-22095-1_95 [GS Search]

CEDETi. (2015). Sueña letras. Obtenido de http://www.cedeti.cl/tecnologiasinclusivas/software-educativo/suenaletras/

Clemente, M., \& Domínguez, A. (2003). La enseñanza de la lectura. Enfoque psicolingüístico y sociocultural. Piramide Ediciones Sa.

Divito, M., Pahud, F., \& Barale, C. (2003). La práctica docente y la alfabetización inicial del niño sordo. Educere, 7(22). Recuperado el 21 de Septiembre de 2019. [GS Search]

Ferreira, M. A., Bueno, J., \& Bonacin, R. (2015). Using computational resources on bilingual deaf literacy: an analysis of benefits, perspectives and challenges. International Conference on Universal Access in Human-Computer Interaction, (págs. 362-372). doi: 10.1007/978-3319-20681-3_34 [GS Search]

Figueroa, V., \& Lissi, M. R. (2005). La lectura en personas sordas: consideraciones sobre el rol del procesamiento fonológico y la utilización del lenguaje de señas. Estudios pedagógicos, 105-119. doi: 10.4067/S0718-07052005000200007 [GS Search] 
Flórez-Aristizábal, L., Cano, S., Collazos, C. A., Benavides, F., Moreira, F., \& Fardoun, H. M. (2019). Digital transformation to support literacy teaching to deaf Children: from storytelling to digital interactive storytelling. Telematics and Informatics, 87-99. doi: 10.1016/j.tele.2018.09.002 [GS Search]

Fourcade, M. (2007). La conciencia fonológica y la escritura del niño sordo.

García, M., Sánchez, M., \& Castro, A. (2012). Habilidades metalingüísticas en educación infantil. Congreso iberoamericano de las Lenguas en la educación y en la cultura. [GS Search]

González, A., Herrera, A., Marín, D., \& Rojas, T. (2008). Planificación cognitiva en niños con déficit auditivo. Pensamiento psicológico, 4(11), 85-104. Obtenido de https://culturasorda.org/wp-

content/uploads/2015/03/Gonzalez_Herrera_Marin_Rojas_Planificacion_cognitiva_nino s_deficit_auditivo_2008.pdf [GS Search]

Hanson, V. L., \& Padden, C. A. (1992). Handson: A multi-media program for bilingual language instruction of deaf children. Proceedings of the Johns Hopkins National Search for Computing Applications to Assist Persons with Disabilities, (págs. 5-6). doi: 10.1109/CAAPWD.1992.217410 [GS Search]

Lissi, M., Grau, V., Raglianti, M., Salinas, M., \& Torres, M. (2001). Adquisición de la lectoescritura en niños sordos: una visión desde los profesores en chile. Psykhe, 10(1), 3548. Obtenido de http://ojs.uc.cl/index.php/psykhe/article/view/19465 [GS Search]

León, J. (2015). La adquisición de la lectura y escritura en niños que presentan discapacidad intelectual leve. Revista: Atlante. Cuadernos de educación y desarrollo. Obtenido de https://www.eumed.net/rev/atlante/05/discapacidad-intelectual.html [GS Search]

Malzkuhn, M., \& Herzig, M. (2013). Bilingual storybook app designed for deaf children based on research principles. Proceedings of the 12th International Conference on Interaction Design and Children, (págs. 499-502). doi: 10.1145/2485760.2485849 [GS Search]

Marchesi, A. (1987). Desarrollo cognitivo y lingüístico de los niños sordos. Perspectivas educativas. Madrid.

Martín, E. (2010). El alumnado con discapacidad auditiva: conceptos clave, clasificación y necesidades. Pedagogía Magna, 5, 89-96.

Mich, O., Pianta, E., \& Mana, N. (2013). Interactive stories and exercises with dynamic feedback for improving reading comprehension skills in deaf children. Computers \& Education, 3444. doi: 10.1016/j.compedu.2013.01.016 [GS Search]

OMS. (15 de marzo de 2019). Sordera y pérdida de la audición. Obtenido de https://www.who.int/es/news-room/fact-sheets/detail/deafness-and-hearing-loss

Ortiz, I. R. (2005). Condiciones para la educación bilingüe de las personas sordas. Revista de logopedia, foniatría y audiología, 28-37. doi: 10.1016/S0214-4603(05)75807-1 [GS Search]

Rusell, G., \& Lapend, M. (2010). Alfabetización de los niños sordos, español como segunda lengua. Obtenido de https://cultura-sorda.org/wpcontent/uploads/2015/03/Rusell_Lapend_Alfabetizacion_alumnos_sordos_espanol_leng ua_segunda_2010.pdf 